\title{
Evaluation of Low Dose Silicon Carbide Temperature Monitors
}

\author{
K. L. Davis ${ }^{1}$, A. Gusarov ${ }^{2}$, T. C. Unruh ${ }^{1}$, P. Calderoni ${ }^{1}$, B. J. Heidrich ${ }^{1}$, K. M. Verner ${ }^{2}$, \\ A. Al Rashdan ${ }^{1}$, A. A. Lambson ${ }^{1}$, S. Van Dyck ${ }^{2}$, I. Uytdenhouwen ${ }^{2}$ \\ ${ }^{I}$ Idaho National Laboratory \\ ${ }^{2}$ SCK-CEN Belgian Nuclear Research Centre
}

\begin{abstract}
Thermocouples are generally used to provide real-time temperature indications in instrumented tests performed at materials and test reactors. Melt wires or paint spots are often included in such tests as an independent technique of detecting peak temperatures incurred during irradiation. In addition, less expensive static capsule tests, which have no leads attached for real-time data transmission, often rely on melt wires and paint spots as a post-irradiation technique for peak temperature indication. Unfortunately, these techniques are limited in that they can only detect whether a single temperature is or is not exceeded. Silicon carbide (SiC) monitors are advantageous because a single monitor can be used to determine the peak temperature reached within a relatively broad

range $\left(200-800^{\circ} \mathrm{C}\right)$. Although the use of $\mathrm{SiC}$ monitors was proposed more than five decades ago, the ultimate performance limits of this technique are not fully understood. The Nuclear Science User Facilities (NSUF) is the United States Department of Energy Office of Nuclear Energy's only designated nuclear energy user facility. Its mission is to provide nuclear energy researchers access to world-class capabilities and to facilitate the advancement of nuclear science and technology. This mission is supported by providing access to state-of-the-art experimental irradiation testing, post irradiation examination facilities, and high performance computing capabilities as well as technical and scientific assistance for the design and execution of projects. As part of an NSUF project, low dose silicon carbide monitors were irradiated in the Belgian Reactor 2 and were then evaluated both at the SCK•CEN and at Idaho National Laboratory's High Temperature Test Laboratory to determine their peak temperature achieved during irradiation. The technical significance of this work was that the monitors were irradiated to a dose that was significantly less than recommended in published literature. This paper will discuss the evaluation process, the irradiation test, and the performance of the low dose silicon carbide temperature monitors.
\end{abstract}

Keywords-In-pile instrumentation, temperature sensor.

\section{INTRODUCTION}

$\mathrm{S}^{\mathrm{N}}$ INCE the early $1960 \mathrm{~s}$, SiC has been used as a post-irradiation temperature monitor. Several researchers have observed that neutron irradiation induced lattice expansion of $\mathrm{SiC}$ annealed out when the post-irradiation annealing temperature exceeds the peak irradiation temperature. Irradiation temperature is determined by measuring a property

change after isochronal annealing or during a continuously monitored annealing process [1-8]. There are many properties that may be measured including, electrical resistivity, density, thermal diffusivity, and lattice spacing. In general, electrical resistivity is accepted as a robust measurement technique resulting in accuracies within $20^{\circ} \mathrm{C}$ [9].

Twelve silicon carbide $(\mathrm{SiC})$ temperature monitors were irradiated in the Belgian Reactor 2 (BR2) as part of a Nuclear Science Users Facilities (NSUF) Project and were delivered to the High Temperature Test Lab (HTTL) for evaluation to determine their peak temperature achieved during irradiation. Each monitor had a sister monitor exposed to identical irradiation test conditions. Monitors with the "A" designation (six in total) were evaluated using an electrical resistivity method [10]. Sister monitors with the "B" designation are to be evaluated using a new method [11]. The evaluation of the "B" temperature monitors will not be described in this report, but will be described in a subsequent report once the evaluations have been completed. TABLE I provides identification for each "A" monitor with its dose and an expected peak irradiation temperature based on thermal analysis.

The quality of material used to manufacture the $\mathrm{SiC}$ temperature monitor has a major impact on the radiation-induced swelling and, thus, the ensuing peak irradiation temperature evaluation. Temperature monitors were fabricated from material meeting the Rohm Haas specification SC003. This material was produced via chemical vapor deposition (CVD) process with a high purity (99.9995\%) and a density equal to theoretical. No voids or micro cracks were allowed. Independent verification was not performed. Due to its polycrystalline $\beta$-cubic structure, the $\mathrm{SiC}$ material characteristics are isotropic. Using this characteristic, the $\mathrm{SiC}$ monitors were manufactured to exceed a resistivity $>1000 \mathrm{ohm} / \mathrm{m}$. SiC monitors used in the experiment were manufactured as cylinders with a $1 \mathrm{~mm}$ diameter and a $12.5 \mathrm{~mm}$ length (Fig. 1).

This report discusses the laboratory evaluation method, the irradiation capsule design, thermal analysis, dose calculations, evaluation of the $\mathrm{SiC}$ monitors, and subsequent computed tomography evaluations.

\section{METHOD}

HTTL uses resistivity measurements to infer peak irradiation temperature [12-14]. SiC monitors may be evaluated for peak irradiation temperatures ranging from 150 $-800^{\circ} \mathrm{C}$ with a recommended dose ranging from $1-8 \mathrm{dpa}$ [10]. For this evaluation, the temperature criterion was met, but it is significant to note $\mathrm{SiC}$ monitors with the M1 designation received a dose that was half the minimal 
recommended dose.

Fig. 2 depicts the equipment at the HTTL used to evaluate the SiC monitors. The $\mathrm{SiC}$ monitors are heated in the annealing furnace using isochronal temperature steps. Annealing temperatures are recorded using a National Institute of Standards and Technology (NIST) traceable thermocouple inserted into an alumina tube in the furnace. After each isochronal annealing, the specimens are placed in a resistivity measurement fixture located in the constant temperature chamber (maintained at $40^{\circ} \mathrm{C}$ ) for a minimum of 30 minutes. After the 30 minute wait time, each specimen's resistance is measured. Thanks to the high thermal conductivity of SiC 30 minutes is more than sufficient to achieve thermal equilibrium.

\section{IRRADIATION CAPSULE}

The reactor exposure was performed using the Basket for Material Irradiation (BAMI) rig of the BR2, using standard non-instrumented capsules. The capsule consists of an external aluminum body which is hermetically sealed in a He atmosphere at two bar pressure using plastic deformation. To provide a required temperature under radiation, samples were inserted into a dedicated holder. In the present experiment, this holder included three sections made as thick-wall stainless steel tubes separated by ceramic spacers. The crosssection of the capsule is schematically shown in Fig. 3 (a) and a photograph of the holders and spacers is shown in Fig. 3 (b). Each $15 \mathrm{~mm}$ long stainless steel section had four symmetrically located $1.1 \mathrm{~mm}$ diameter channels, in which the $\mathrm{SiC}$ monitors were inserted. The $0.1 \mathrm{~mm}$ difference in the channel and the sample diameter was made to allow easy retrieval of the $\mathrm{SiC}$ samples after irradiation.

The $5 \mathrm{~mm}$ thick spacers were made of low thermal conductivity $(\mathrm{k}=1.3 \mathrm{~W} / \mathrm{mK})$ Alumo-silicate Aremcolox $502-1100$ ceramic with a density of $2.70 \mathrm{~g} / \mathrm{cm}^{3}$. This material can sustain long-term temperatures up to $1200^{\circ} \mathrm{C}$ (melting at $\sim 1600^{\circ} \mathrm{C}$ ). Impurities include $\mathrm{Fe}_{2} \mathrm{O}_{3}, \mathrm{MnO}, \mathrm{MgO}, \mathrm{CaO}, \mathrm{TiO}_{2}$, $\mathrm{K}_{2} \mathrm{O}, \mathrm{Na}_{2} \mathrm{O}, \mathrm{P}_{2} \mathrm{O}_{5}, \mathrm{C}$, and $\mathrm{S}$ with the total amount less than $3 \%$ by mass. The spacers provide thermal insulation between different sections, serve to center the plugs on the body axis, and keep the $\mathrm{SiC}$ samples in the channels.

\section{THERMAL ANALYSIS}

The capsule has no active heating element; the temperature of the samples during irradiation is defined by the thermal balance between the radiation heat generation in the internal components and heat transfer through the He gas gap and the aluminum body to the reactor cooling water. Therefore, for a given radiation heating level, the inner and outer diameters of the stainless steel holder can be adjusted to obtain a desirable irradiation temperature.

The following phenomena were considered to define the temperature distribution:

1) heat generation inside the holder, spacers, and in the capsule walls,

2) heat exchange through the different materials inside the capsule, including gas gaps,

3) heat exchange on the capsule surface.

The volumetric heat generation is dominated by the gamma heating and can be found using a simple approximation:
$q=Q \rho$

where Q $[\mathrm{W} / \mathrm{g}]$ is gamma heat generation in reference material (aluminum), which is standard material for BR2 gamma-heating evaluation, and $\rho$ is the material density of a component. Heat generation in stainless steel holders is slightly higher. This difference was neglected because it is comparable with the uncertainty of the computational model.

In a closed capsule filled with He gas and small gaps, there is no forced convection, and the influence of the natural convection is small. The maximum temperature considered was $400^{\circ} \mathrm{C}$. For this temperature, the radiative heat transfer was negligible when compared to the conduction. Therefore, heat exchange occurs via heat conduction mechanism. For the irradiation, the capsule was placed inside a standard BR2 driver fuel element which was cooled with a water flow at $\sim 10 \mathrm{~m} / \mathrm{s}$. It is known that the cooling of the fuel elements occurs in

a mono-phase (no boiling) regime. This means that the heat exchange conditions were well defined, and the temperature of the capsule external surface was maintained between 48$52^{\circ} \mathrm{C}$ throughout the irradiation. A $50^{\circ} \mathrm{C}$ temperature was used for the capsule design. This conclusion is consistent with the thermal balance calculations below. The design parameters are summarized in TABLE II.

Compared to steel and aluminum, He gas has a relatively low thermal conductivity. As a result, the holder-body gap thickness has a big influence on the holder temperature. This made it possible to obtain three different temperatures in one capsule by fabricating the sections with different He gap thicknesses. The gap between the spacers and the capsule body was minimized to prevent excessive He leakage and to provide accurate centering of the plugs, yet was made large enough to allow for capsule dismantling.

Due to the low thermal conductivity of the spacers and the geometry on the BAMI rig, heat flux in the axial direction is much lower when compared to heat flux in the radial direction. Therefore, the temperature distribution calculation problem is effectively reduced to an axially symmetric 2D problem. This allowed use of the analytical approach for the preliminary capsule design.

For the preliminary design, the system of the heat transfer equations was solved analytically:

$\frac{1}{r} \frac{d}{d r}\left(k_{i} r \frac{d T_{i}}{d r}\right)+q_{i}=0, i=1 \ldots n$

where $i$ is the layer number, $\mathrm{n}=4$. The following boundary conditions were applied:

$T_{1}(0)<\infty$

$T_{i}\left(r=r_{i}\right)=T_{i+1}\left(r=r_{i}\right)$

$k_{i} \frac{d T_{i}}{d r}\left(r=r_{i}\right)=k_{i+1} \frac{d T_{i+1}}{d r}\left(r=r_{i}\right)$

$-k_{n} \frac{d T_{n}}{d r}\left(r=r_{n}\right)=h\left[T_{n}\left(r_{n}\right)-T_{\infty}\right]$

where $T_{\infty}$ is the coolant temperature.

The thermal expansion of the capsule components was 
taken into account by defining the dimensions at the design temperature. The analytical model was verified using ANSYS numerical simulations. The difference was less than $10^{\circ} \mathrm{C}$. The numerical simulations were used for the part fabrication. Calculated peak irradiation temperatures were presented in TABLE I.

\section{Dose Calculation}

Two identical capsules (M1 and M2) were prepared. The capsule M1 was exposed in the BR2 reactor during two cycles and the capsule M2 during the first cycle only. The irradiation was performed by placing the capsules inside BR 2 driver fuel elements with a high burn-up located in the same B120 channel for both cycles. The capsules were dismounted simultaneously following a two month cooling period after the end of the second cycle. The channel selection was done based on the pre-cycle neutronic Monte-Carlo computations. The estimated irradiation conditions are given in TABLE III. The nominal reactor power during two cycles was the same. The gamma-heating levels in the irradiation channel during the two cycles were nearly identical, which means that the temperatures of the samples were also nearly the same. The difference in the neutron fluxes of $\sim 10 \%$ is related with a lower fuel burn-up in the second cycle.

DPA calculations were completed using flux outputs from MCNP [15] and displacement cross sections from SPECTER [16]. SPECTER is a computational tool developed at Argonne National Laboratory to assist in material damage calculations. The DPA rate is calculated using,

$$
D P A_{\text {rate }}=\int_{E_{m}}^{E_{M}} \sigma_{d}(E) \phi(E) d E
$$

with $\sigma_{\mathrm{d}}$ being the 41 elemental displacement cross sections from SPECTER and $\phi$ being the neutron flux. Both variables are energy dependent and 100 energy groups from $E_{m}$ and $E_{M}$, 0 to $20 \mathrm{MeV}$ respectively, were used for the calculation. The displacement cross sections are calculated with

$\sigma_{d}=\frac{0.8 E_{a}}{2 E_{d}}$

where;

$E_{a}$ is the available energy that is found in the SPECTER manual or can be calculated using NJOY [17],

$E_{d}$ is the displacement threshold energy, which is also found in the SPECTER manual.

Using the ATR MCNP neutron flux results, the experimental positions with the most similar conditions to those in the BR2 experiment were found [18]. The fast and thermal fluxes of $\mathrm{E}<0.5 \mathrm{eV}$ and $\mathrm{E}>0.1 \mathrm{MeV}$ are much higher in the BR2 reactor than in the ATR. However, the ratio of fast to thermal flux can be used to compare the two differing neutron fluxes. After finding the most similar fast to thermal ratio in the ATR experimental position, the ratio of the BR2 fast flux to the ATR fast flux was found and used as a multiplier for the DPA rate. The DPA rates of silicon and carbon in ATR are 36 days/DPA and 60 days/DPA, respectively. To calculate the DPA rate of the compound, a weighted average is taken based on the atom fraction of silicon and carbon in SiC. This has been shown to be a reasonable method of approximating compound material displacement cross sections when compared to tools like SPECOMP [19] that calculate compound displacement cross sections. Lastly, the time for each experiment is multiplied by the DPA rate, and the actual DPA is found. At 21 days, the DPA is approximately 0.5 and 1.0 at 49 days.

A second irradiation DPA calculation was also performed. The cycle irradiation conditions were calculated using MCNP. The experiment, Motore, was located at the midplane of the reactor core within a fuel element in channel B120. To evaluate the irradiation conditions, F4 tally cards were used, which calculate the neutron flux averaged over a cell in neutrons $/ \mathrm{cm}^{2} \mathrm{~s}$. This calculated value is normalized to obtain the actual neutron flux in the region of interest. The F4 tally normalized result was used for calculating the flux spectrum and the DPA. Fig. 4 presents the neutron flux spectra on the capsules. The DPA is approximately 0.5 and 1.1 at 21 and 49 days, respectively. This updated calculated DPA is in close agreement with the first calculation. The doses for each $\mathrm{SiC}$ monitor were presented in TABLE I.

\section{SiC Temperature Monitor Evaluations}

This section discusses the evaluation of the SiC monitors and presents the results. This work was conducted in accordance with an approved evaluation plan [10].

An ohmic response curve was generated for each monitor prior to heating. Monitor BR2 M1-High-A exhibited a typical ohmic response and is displayed in Fig. 5. These data were used to check for linearity and to select a target voltage (with corresponding current) that would result in minimal heating of the $\mathrm{SiC}$ monitor during resistance testing and remain within the range of the test instrumentation. For this evaluation, voltage ranged from $16-20 \mathrm{~V}$.

Electrical resistivity is used by HTTL to infer the peak irradiation temperature [1]. Figs. $6-11$ present the resistivity data taken at each isochronal annealing temperature for each $\mathrm{SiC}$ temperature monitor. The peak irradiation temperature, using an electrical resistivity technique, can be taken as the point where the resistivity begins and consistently remains, above the error band. The error band bounds the data and is represented by the dotted lines. For this evaluation, the error band was established as the $\pm 2 \sigma$ value based on a sample size of the first five data points taken below $150^{\circ} \mathrm{C}$.

TABLE IV shows the results for the evaluation. The calculated versus measured peak irradiation temperatures had good agreement comparable to published data [9]. This result is significant considering that $\mathrm{M} 1 \mathrm{SiC}$ monitors received doses that were much less than $1 \mathrm{dpa}$.

As evident from the presented data (Figs. 6-11), all of the monitors responded well with the exception of the BR2 M2Low-A (see Fig. 10). This temperature monitor received the lowest dose $(0.5 \mathrm{dpa})$ and was exposed to the lowest temperature $\left(255^{\circ} \mathrm{C}\right)$. Also the error band was much larger than expected. There are several factors that may be considered as to why BR2 M2-Low-A did not respond to the isochronal heating. Further analysis such as microscopy, computed tomography, and material analysis could be used to determine why M2-Low-A did not respond. Computed tomography was performed and is discussed below. 


\section{COMPUTED TOMOGRAPHY EVALUATION}

In an effort to uncover the cause of the indeterminate response of monitor BR2 M2-Low-A, 3D micro-focus computed tomography (CT) was performed on this monitor and on BR2 M1-LOW-A for comparison. The scan energy was $50 \mathrm{kV}$ at a resolution of $6 \mu \mathrm{m}$. The purpose for performing $\mathrm{CT}$ was to determine if there were any defects (voids, cracks, porosity, etc.) or foreign material in the BR2 M2-LOW-A monitor that would singularize it from the BR2M1-LOW-A monitor. Figs. 12 and 13 show CT slices taken from each scan. After evaluating the scans, no apparent anomalous indications were found in the BR2 M2-Low-A monitor. It interesting to note that high density indications were found on or near the surface of the BR2 M1-Low-A monitor, the monitor that performed well.

Both monitors should have been identical in composition. As evident in the scan data, high density material was found on or near the surface of the BR2 M1-Low-A monitor. Visual inspection of the monitor did not find material on the surface; however, it is believed that the material is platinum which transferred from the resistivity measurement apparatus and that it did not influence the annealing behavior. Resistivity measurements were taken after the evaluation but before the CT scan. 3D micro-focus CT did not uncover a plausible cause for the indeterminate response of the BR2 M2-Low-A monitor.

\section{CONCLUSION}

$\mathrm{SiC}$ temperature monitors were irradiated in BR2 as part of an NSUF Project and evaluated at the HTTL to determine their peak temperature achieved during irradiation. Dedicated irradiation capsules were designed and fabricated to allow irradiation at specified temperatures ranging from $240-380^{\circ} \mathrm{C}$. After the irradiation, the peak irradiation temperature of each monitor was evaluated using the resistance measurement method. This method recommends a minimum dose of $1 \mathrm{dpa}$. These monitors received doses ranging from $0.5-1.1 \mathrm{dpa}$. Deviations between the calculated temperature and the evaluated temperature were within or near published limits. A significant finding from this evaluation is that it is possible to evaluate $\mathrm{SiC}$ temperature monitors at dose levels much less than $1 \mathrm{dpa}$. SiC monitors were successfully evaluated that were irradiated to $0.5 \mathrm{dpa}$ with temperatures ranging from $240-380^{\circ} \mathrm{C}$.

\section{REFERENCES}

[1] J. L. Rempe, K. G. Condie, D. L. Knudson, and L.L. Snead, Silicon Carbide Temperature Monitor Measurements at the High Temperature Test Laboratory, INL/EXT-10-17608, January 2010.

[2] L. L. Snead, A. M. Williams, and A. L. Qualls, "Revisiting the use of $\mathrm{SiC}$ as a Post Irradiation Temperature Monitor," Effects of Radiation on Materials, ASTM STP 1447, M L. Grossbeck, Ed, ASTM International, West Conshohocken, PA, 2003.

[3] K. G. Field, J. L. McDuffee, J. W. Geringer, C. M. Petrie, Y. Katoh, "Evaluation of the Continuous Dilatometer Method of Silicon Carbide Thermometry for Passive Irradiation Temperature Determination," Nuclear Instruments and Methods in Physics Research Section B: Beam Interactions with Materials and Atoms, Volume 445, 15 April 2019, Pages 46-56

[4] A. A. Campbell, W. D. Porter, Y. Katoh, and L. L. Snead, "Method for Analyzing Passive Silicon Carbide Thermometry with a Continuous Dilatometer to Determine Irradiation Temperature," Nuclear Instruments and Methods in Physics Research Section B: Beam Interactions with Materials and Atoms, Volume 370, March 2016, Pages 49-58

[5] N.F. Pravdyuk, V.A. Nikolaenko, V.I. Karpuchin, V.N. Kuznetsov, Investigation of Diamond and Silicon Carbide as Indicators of Irradiation Conditions, in: D.J. Littler (Ed.), International Conference on Properties of Reactor Materials and the Effects of Radiation Damage, Butterworths, Gloucestershire, England, 1962, pp. 57-62.

[6] J.I. Bramman, A.S. Fraser, W.H. Martin, Temperature Monitors for Uninstrumented Irradiation Experiments, J. Nucl. Eng. 25 (6) (1971) 223-240.

[7] H. Suzuki, T. Iseki, M. Ito, Annealing Behavior of Neutron Irradiated b-SiC, J. Nucl. Mater. 48 (3) (1973) 247-252.

[8] J.E. Palentine, The Development of Silicon Carbide as a Routine Irradiation Temperature Monitor, and Its Calibration in a Thermal Reactor, J. Nucl. Mater. 61 (3) (1976) 243-253.

[9] Joy L. Rempe, Keith G. Condie, Darrell L. Knudson, and Lance L. Snead, "Comparison Measurements of Silicon Carbide Temperature Monitors", IEEE TRANSACTIONS ON NUCLEAR SCIENCE, VOL. 57 , NO. 3, JUNE 2010.

[10] K.L. Davis and T.C. Unruh, "Silicon Carbide Temperature Monitor Evaluation.” PLN-3473, Rev. 2, Idaho National Laboratory, February 2018.

[11] A. Al Rashdan, K. Davis, T. Unruh, and J. Daw, "Silicon Carbide Temperature Monitor Online Evaluation," PLN-5465, September 2017.

[12] K. L. Davis, B. M. Chase, T. C. Unruh, D. L. Knudson, J. L. Rempe, Drexel University Temperature Sensors, INL/EXT-14-33067, September 2014.

[13] B. M. Chase, J. L. Rempe, K. L. Davis, Evaluation of Temperature Sensors from the EPRI Zirconium Growth Irradiation Tests, INL/LTD14-32210, June 2014.

[14] K. L. Davis, D. L. Knudson, J. L. Rempe, and B. M. Chase, University of Illinois Temperature Sensors, INL/EXT-14-33136, September 2014.

[15] C.J. Werner, et al., "MCNP6.2 Release Notes", Los Alamos National Laboratory, report LA-UR-18-20808 (2018).

[16] L.R. Greenwood and R.K. Smither. SPECTER: Neutron damage calculations for materials irradiations. Technical report, Argonne National Lab., ANL-FPP/TM-197, (1985).

[17] U. Ficher, S.P. Simakov, A.Y. Konobeyev. Assessment of survived radiation defects by a modified version of NJOY, report jeff-doc-1223. Technical report, NEA Data Bank, 2007.

[18] J.A. Mascitti and M. Madariaga. Method for the calculation of DPA in the reactor pressure vessel of atucha ii. Science and Technology of Nuclear Installations, 2011.

[19] LR Greenwood. Specomp calculations of radiation damage in compounds. In Reactor Dosimetry: Methods, Applications, and Standardization. ASTM International, 1989. 


\section{Tables}

TABLE I

BR2 SIC TEMPERATURE MONITORS

Calculated Peak

Irradiation Temperature

\begin{tabular}{ccc} 
Monitor Identification & Dose (dpa) & Trradiation Temperature \\
\hline BR2 M1-Low-A & 0.5 & $255^{\circ} \mathrm{C}$ \\
BR2 M2-Low-A & 1.1 & $255^{\circ} \mathrm{C}$ \\
BR2 M1-High-A & 0.5 & $310^{\circ} \mathrm{C}$ \\
BR2 M2-High-A & 1.1 & $310^{\circ} \mathrm{C}$ \\
BR2 M1-Med-A & 0.5 & $410^{\circ} \mathrm{C}$ \\
BR2 M2-Med-A & 1.1 & $410^{\circ} \mathrm{C}$ \\
\hline
\end{tabular}

TABLE II

MATERIAL CHARACTERISTICS USED IN THERMAL COMPUTATIONS, $\mathrm{Q}=10 \mathrm{~W} / \mathrm{G}$

\begin{tabular}{cccccc}
\hline Layer $n$ & Material & $\begin{array}{c}\text { External radius } r, \\
\mathrm{~mm}\end{array}$ & $\begin{array}{c}\text { Density } \rho, \\
\mathrm{g} / \mathrm{cm}^{3}\end{array}$ & $\mathrm{~W} / \mathrm{m} \mathrm{K} @ 225^{\circ} \mathrm{C}$ & $\begin{array}{c}\mathrm{q}, \\
\mathrm{W} / \mathrm{m}^{3}\end{array}$ \\
\hline $\mathbf{1}$ & $\mathrm{He}$ & 4 & $1.61 \mathrm{E}-07$ & 0.22 & $1.61 \mathrm{E}+00$ \\
$\mathbf{2}$ & Steel plug & $6.45 / 6.325 / 5.925$ & $7.85 \mathrm{E}+00$ & 16.00 & $7.85 \mathrm{E}+07$ \\
$\mathbf{3}$ & $\mathrm{He}$ & 6.7 & $1.61 \mathrm{E}-07$ & 0.22 & $1.66 \mathrm{E}+00$ \\
$\mathbf{4}$ & $\mathrm{Al}$ & 7.5 & $2.70 \mathrm{E}+00$ & 250.00 & $2.70 \mathrm{E}+07$ \\
\hline
\end{tabular}

TABLE III

BR2 IRRADIATION ENVIRONMENT,

\begin{tabular}{|c|c|c|c|}
\hline \multicolumn{2}{|c|}{ BR2 Cycle Information } & Cycle \#1 (1/31/17) & Cycle \#2 (3/14/17) \\
\hline \multicolumn{2}{|c|}{ Reactor Power [MW] } & 55 & 55 \\
\hline \multicolumn{2}{|c|}{ Cycle Length [days] } & 21 & 28 \\
\hline \multicolumn{2}{|c|}{ Fuel Burnup } & $42 \%$ & $28 \%$ \\
\hline$\varphi_{\text {th }}$ & $\begin{array}{l}\mathrm{n} / \mathrm{cm}^{2} / \mathrm{s} \\
\mathrm{E}<0.5 \mathrm{eV}\end{array}$ & $3.27 \mathrm{E}+14$ & $3.03 \mathrm{E}+14$ \\
\hline$\varphi_{\text {fast }}$ & $\begin{array}{l}\mathrm{n} / \mathrm{cm}^{2} / \mathrm{s} \\
\mathrm{E}>0.1 \mathrm{MeV}\end{array}$ & $3.93 \mathrm{E}+14$ & $4.41 \mathrm{E}+14$ \\
\hline Q & $\mathrm{W} / \mathrm{g}$ (in $\mathrm{Al}$ ) & 10.1 & 10.3 \\
\hline$\Phi_{\text {total }}$ & $\mathrm{n} / \mathrm{cm}^{2}$ & $7.13 \mathrm{E}+20$ & $1.07 \mathrm{E}+21$ \\
\hline
\end{tabular}

TABLE IV

EVALUATION RESULTS FOR THE BR2 MONITORS.

\begin{tabular}{|c|c|c|c|c|c|}
\hline ID & Measured & Calculated & $\begin{array}{c}\text { Deviation } \\
\text { (measured - calculated) }\end{array}$ & $\%$ Deviation & $\begin{array}{c}\text { Initial resistivity at } \\
40^{\circ} \mathrm{C}\end{array}$ \\
\hline BR2 M1-Low-A & $240^{\circ} \mathrm{C}$ & $255^{\circ} \mathrm{C}$ & $-15^{\circ} \mathrm{C}$ & $-6 \%$ & $20(\Omega-m)$ \\
\hline BR2 M2-Low-A & Indeterminate & $255^{\circ} \mathrm{C}$ & $\mathrm{n} / \mathrm{a}$ & $\mathrm{n} / \mathrm{a}$ & $16(\Omega-m)$ \\
\hline BR2 M1-High-A & $320^{\circ} \mathrm{C}$ & $310^{\circ} \mathrm{C}$ & $10^{\circ} \mathrm{C}$ & $3 \%$ & $24(\Omega-m)$ \\
\hline BR2 M2-High-A & $330^{\circ} \mathrm{C}$ & $310^{\circ} \mathrm{C}$ & $20^{\circ} \mathrm{C}$ & $6 \%$ & $14(\Omega-m)$ \\
\hline BR2 M1-Med-A & $390^{\circ} \mathrm{C}$ & $410^{\circ} \mathrm{C}$ & $-20^{\circ} \mathrm{C}$ & $-5 \%$ & $43(\Omega-m)$ \\
\hline BR2 M2-Med-A & $380^{\circ} \mathrm{C}$ & $410^{\circ} \mathrm{C}$ & $-30^{\circ} \mathrm{C}$ & $-8 \%$ & $25(\Omega-\mathrm{m})$ \\
\hline
\end{tabular}




\section{Figures}

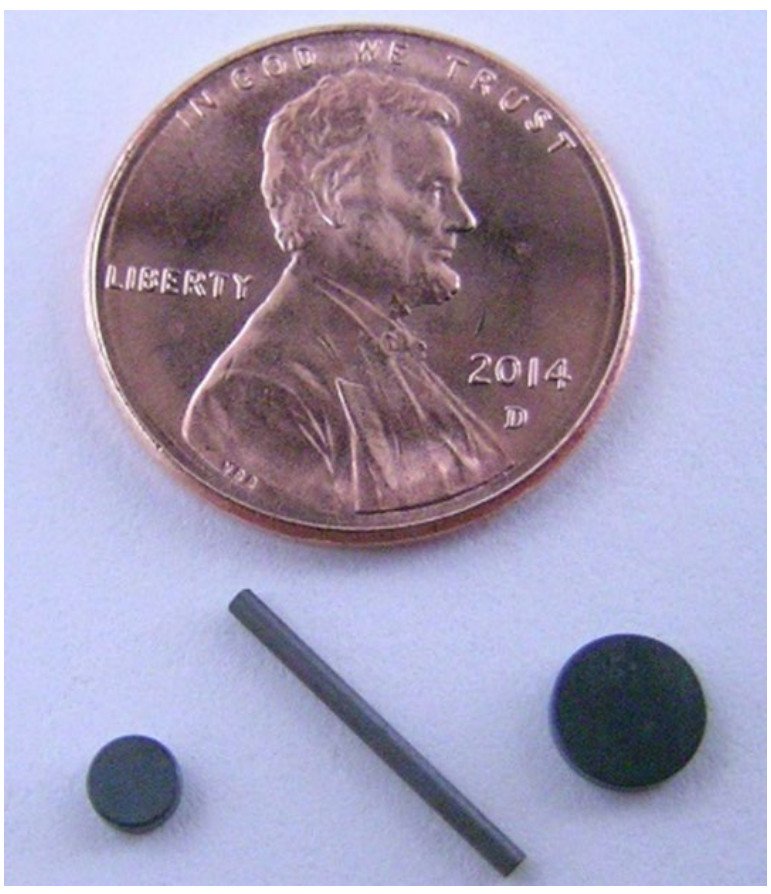

Fig. 1. SiC temperature monitors available for use in irradiation testing include small rods and discs. Only rods were used in this test. Monitors photographed with US cent for size perspective.

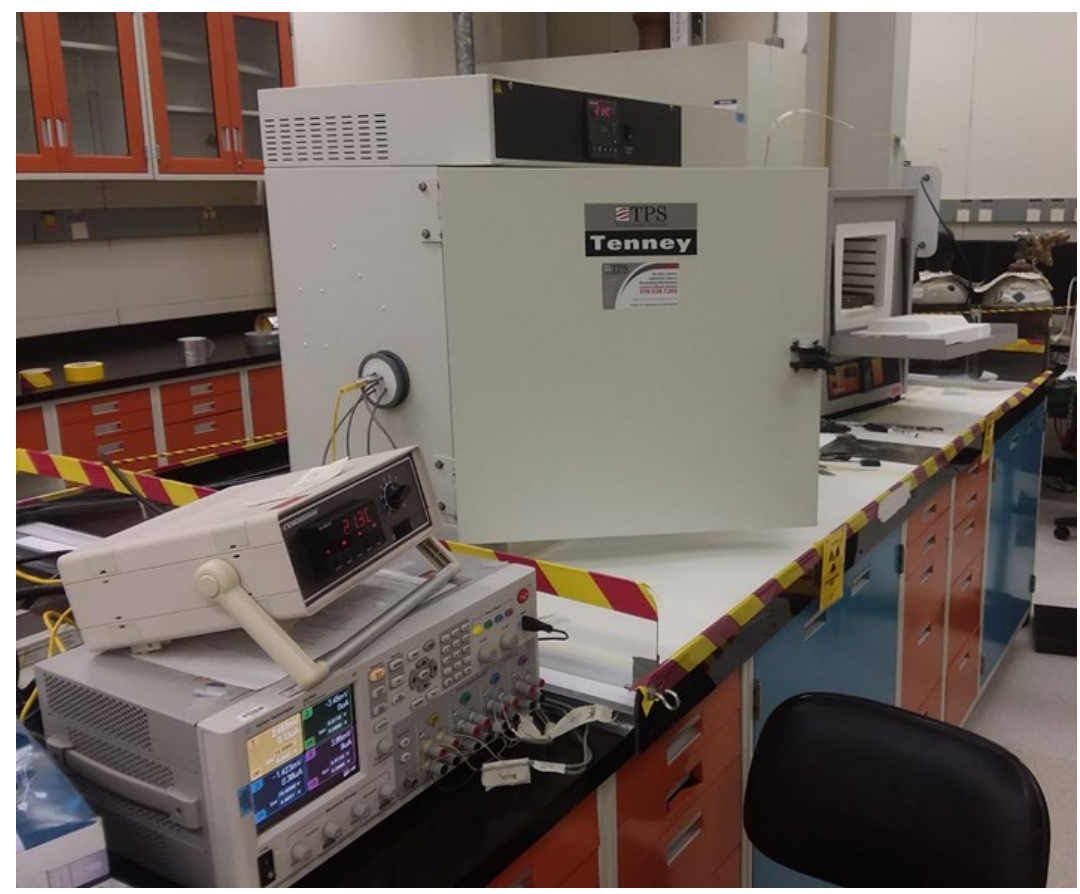

Fig. 2. SiC evaluation system components. 


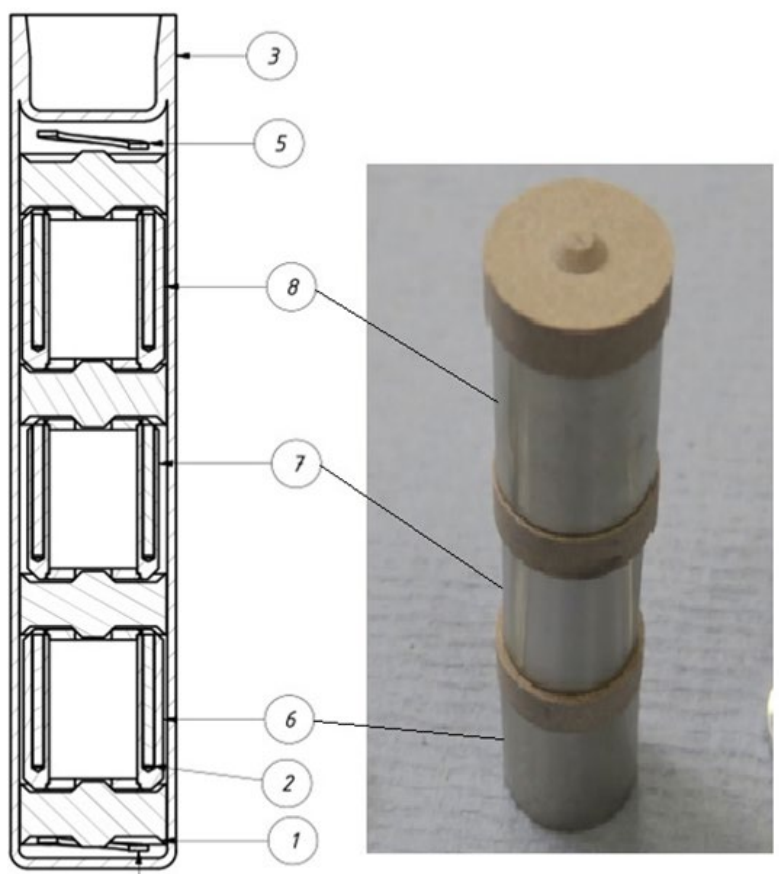

(A)

(B)

Fig. 3. (a) Cross-section of the aluminum irradiation capsule (3), stainless steel holders $(6,7$ and 8 ) for SiC monitors (2). The holders are separated with ceramic discs (1) which are held in place with springs (4 and 5). (b) Photograph of the three holders and the three ceramic spacers stacked before irradiation.

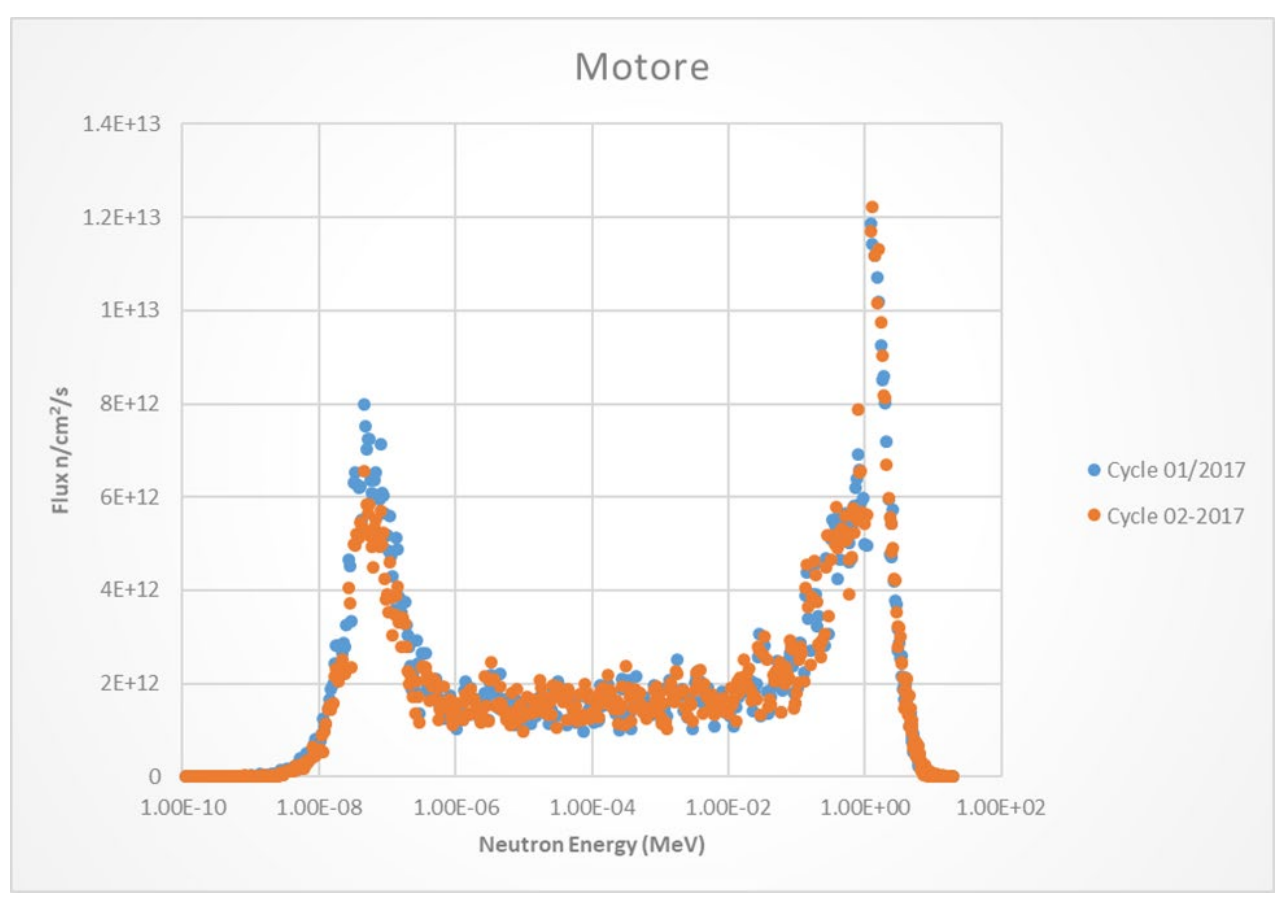

Fig. 4. Neutron flux spectrum on Motore. 


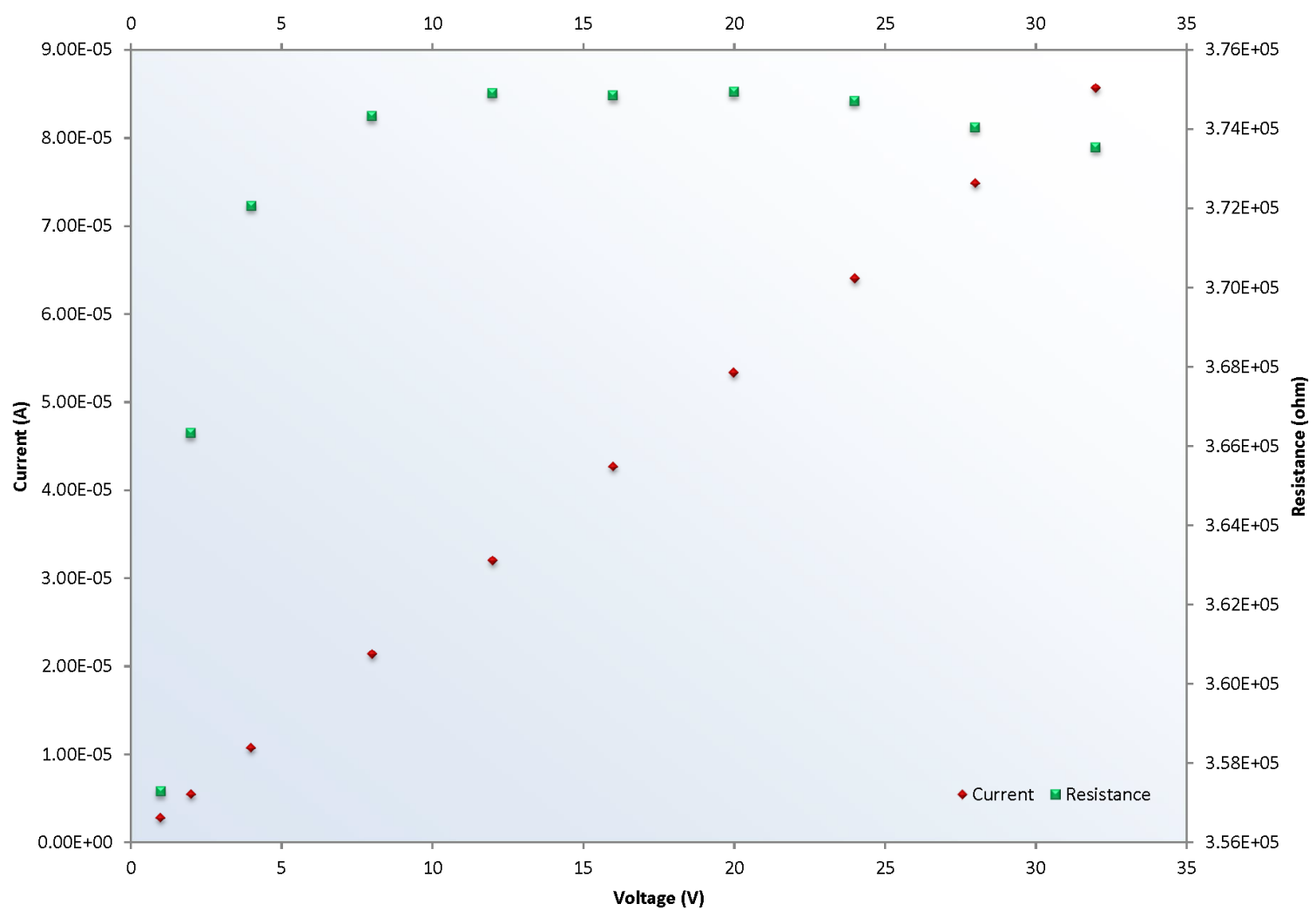

Fig. 5. Typical ohmic response as demonstrated by SiC temperature monitor BR2 M1-High-A.

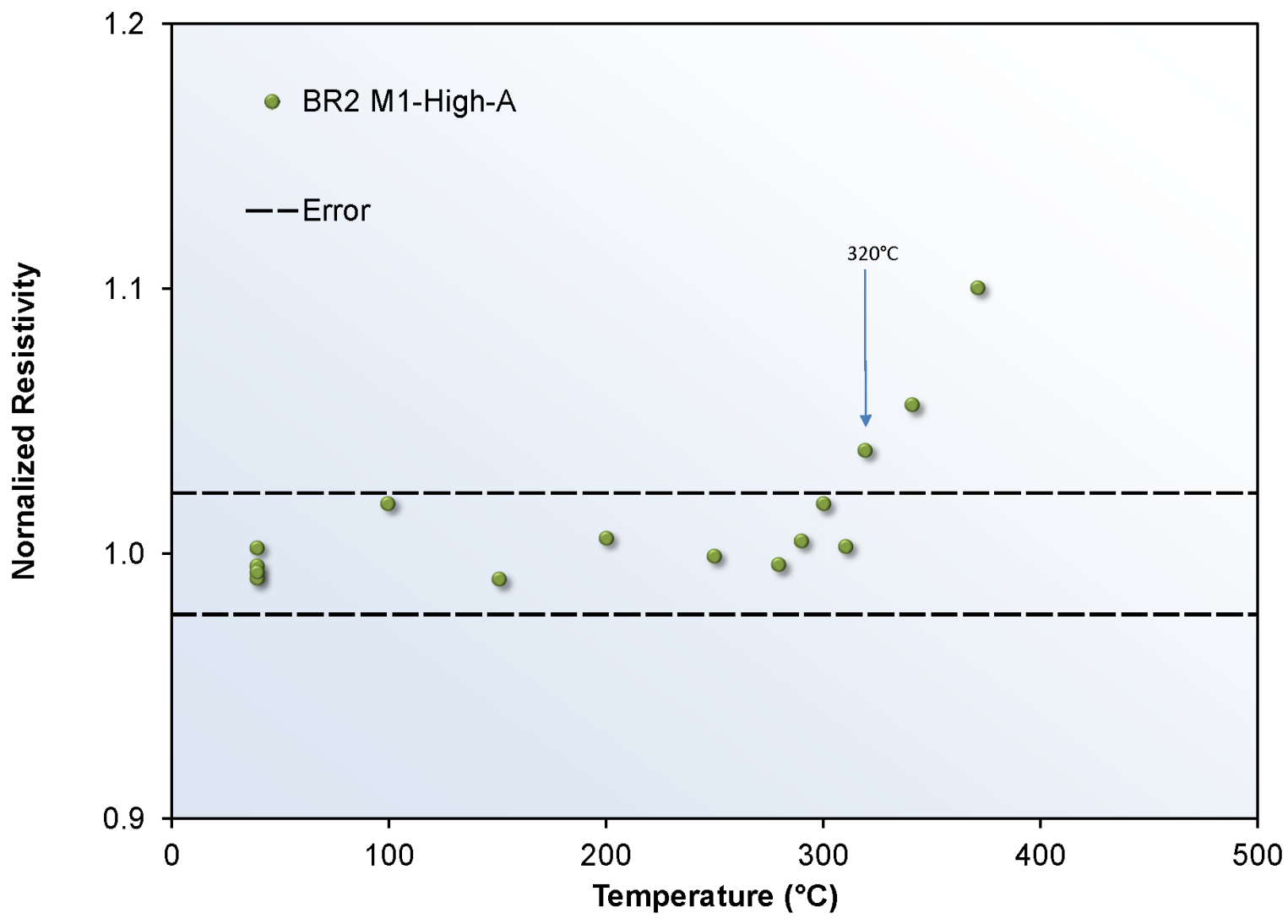

Fig. 6. Resistivity data for BR2 M1-High-A. 


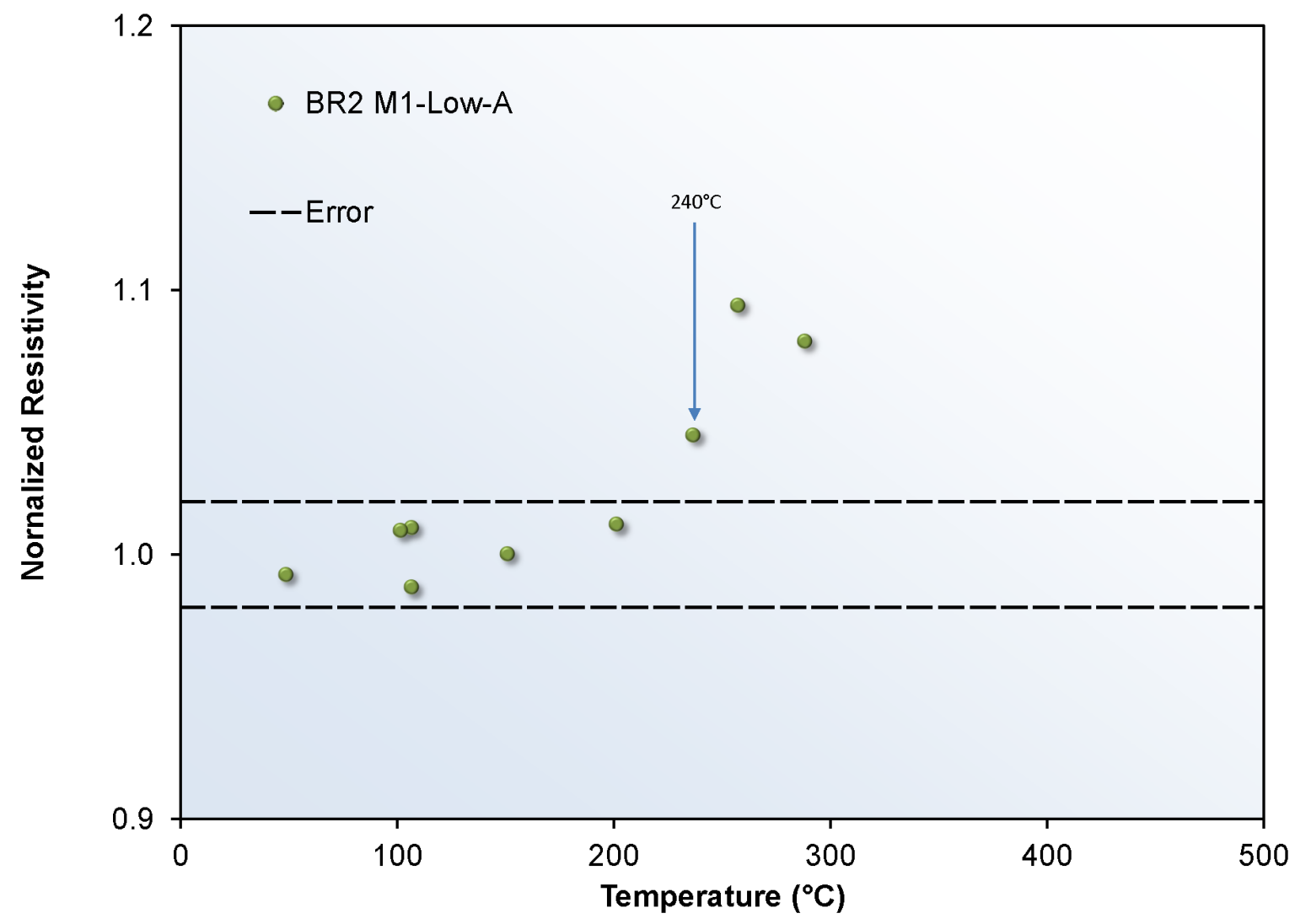

Fig. 7. Resistivity data for BR2 M1-Low-A.

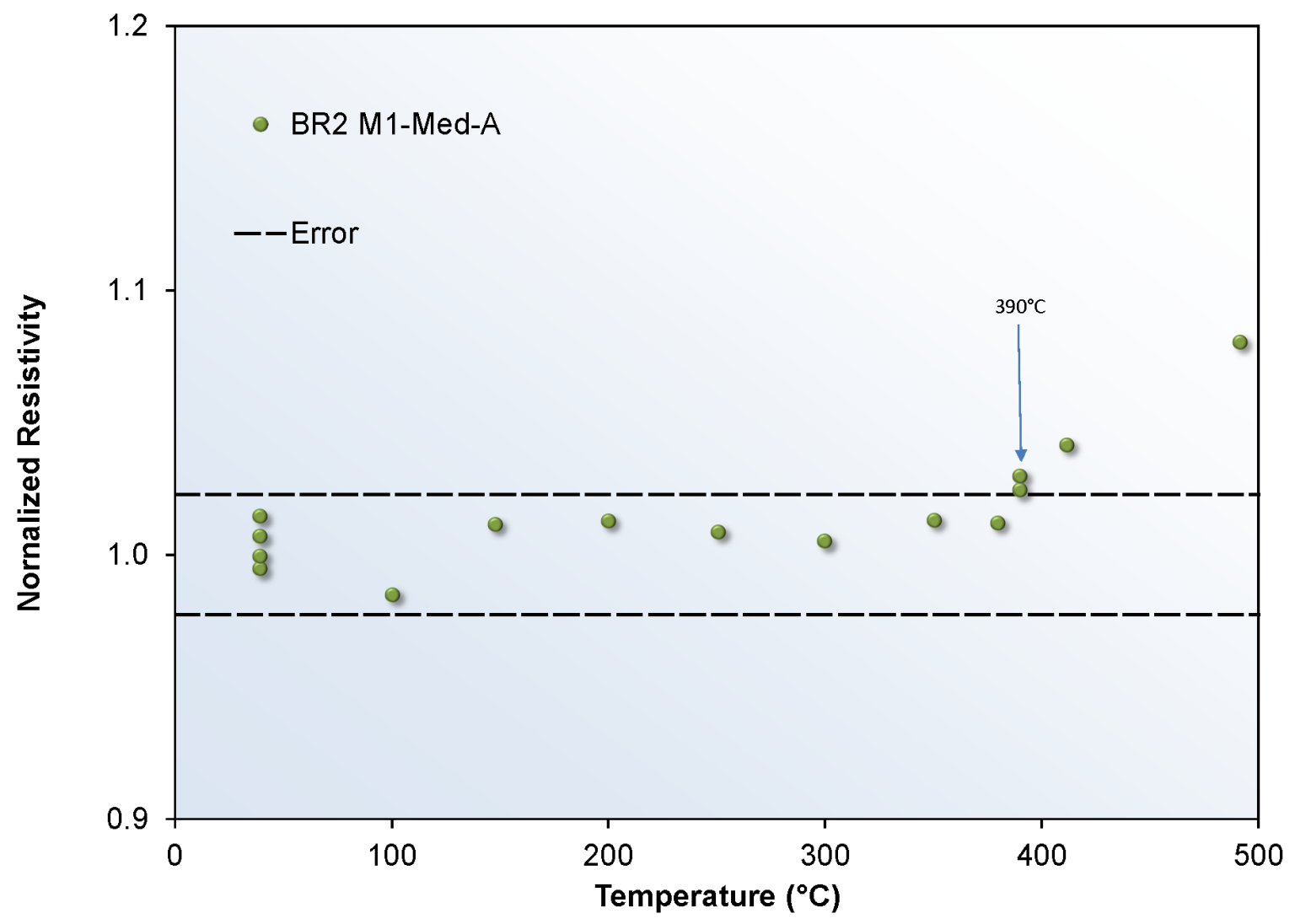

Fig. 8. Resistivity data for BR2 M1-Med-A. 


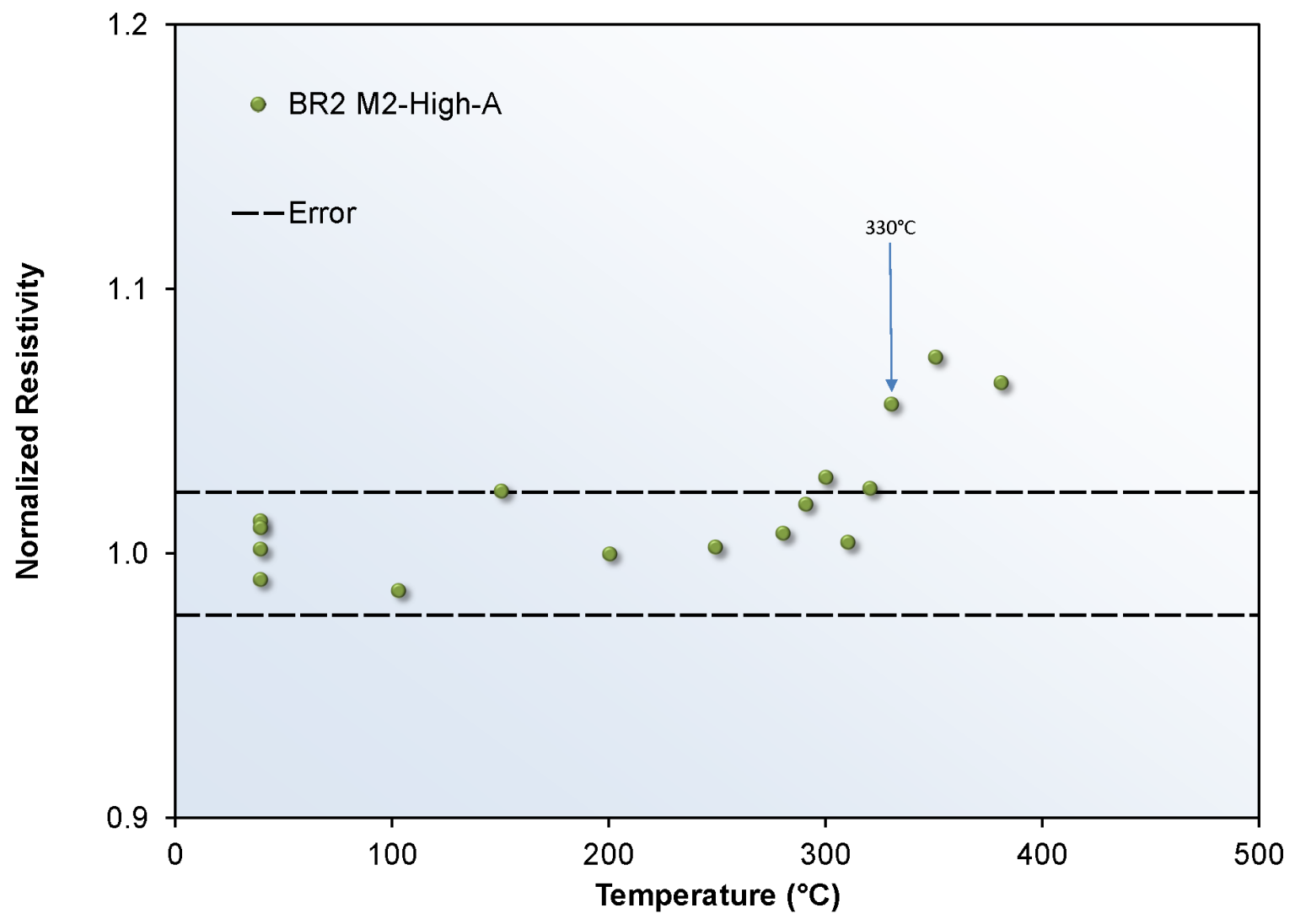

Fig. 9. Resistivity data for BR2 M2-High-A.

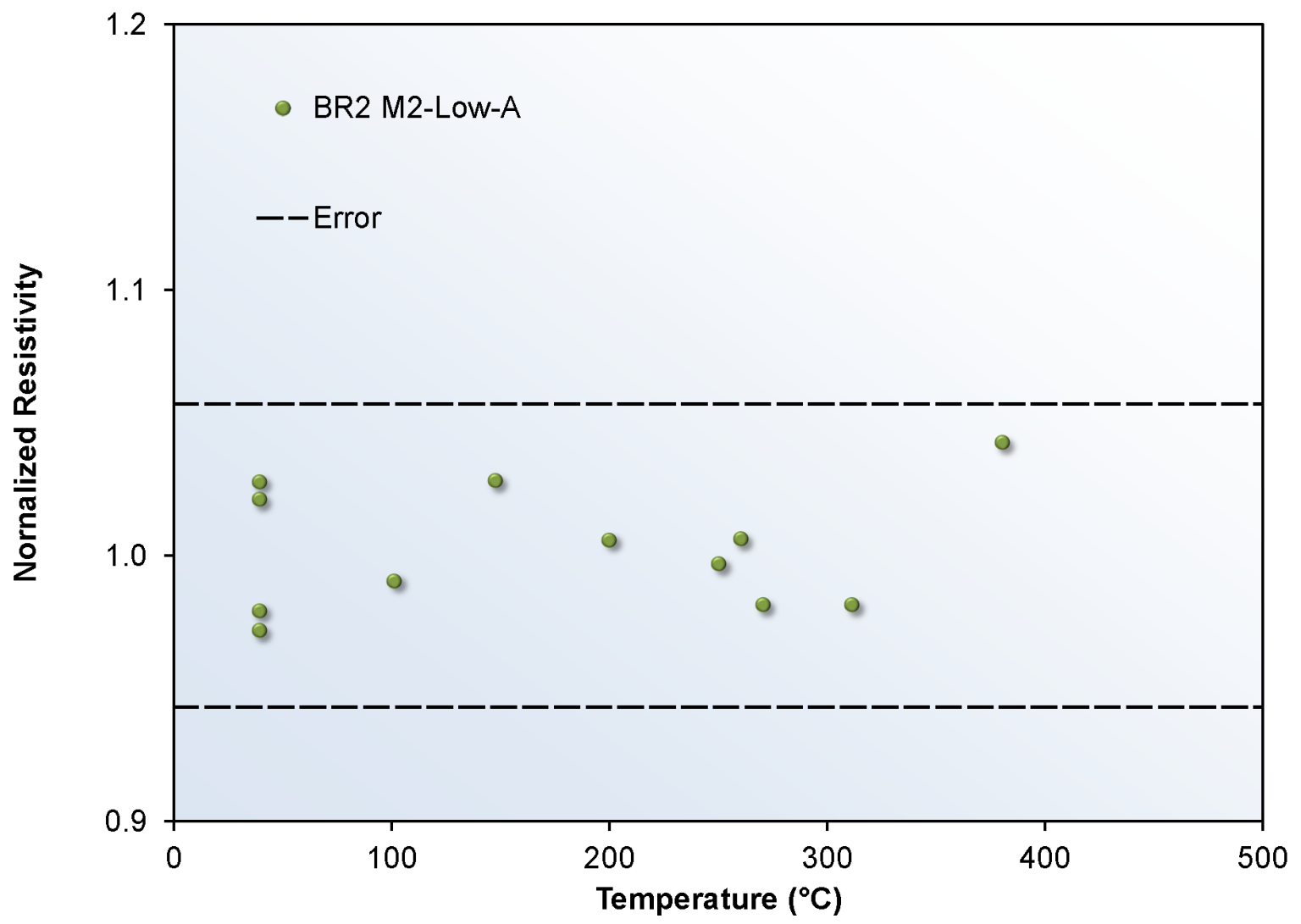

Fig. 10. Resistivity data for BR2 M2-Low-A. 


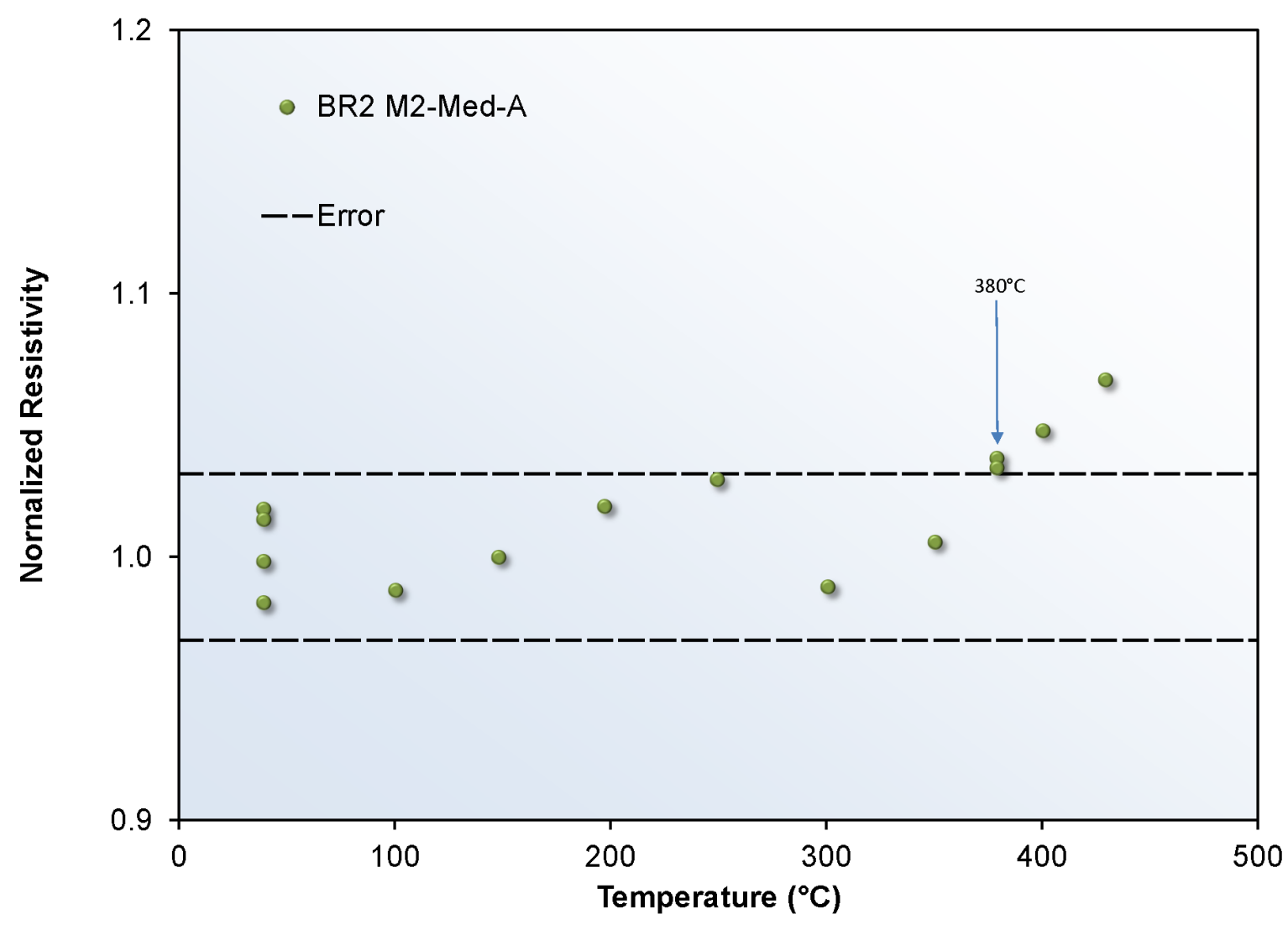

Fig. 11. Resistivity data for BR2 M2-Med-A.

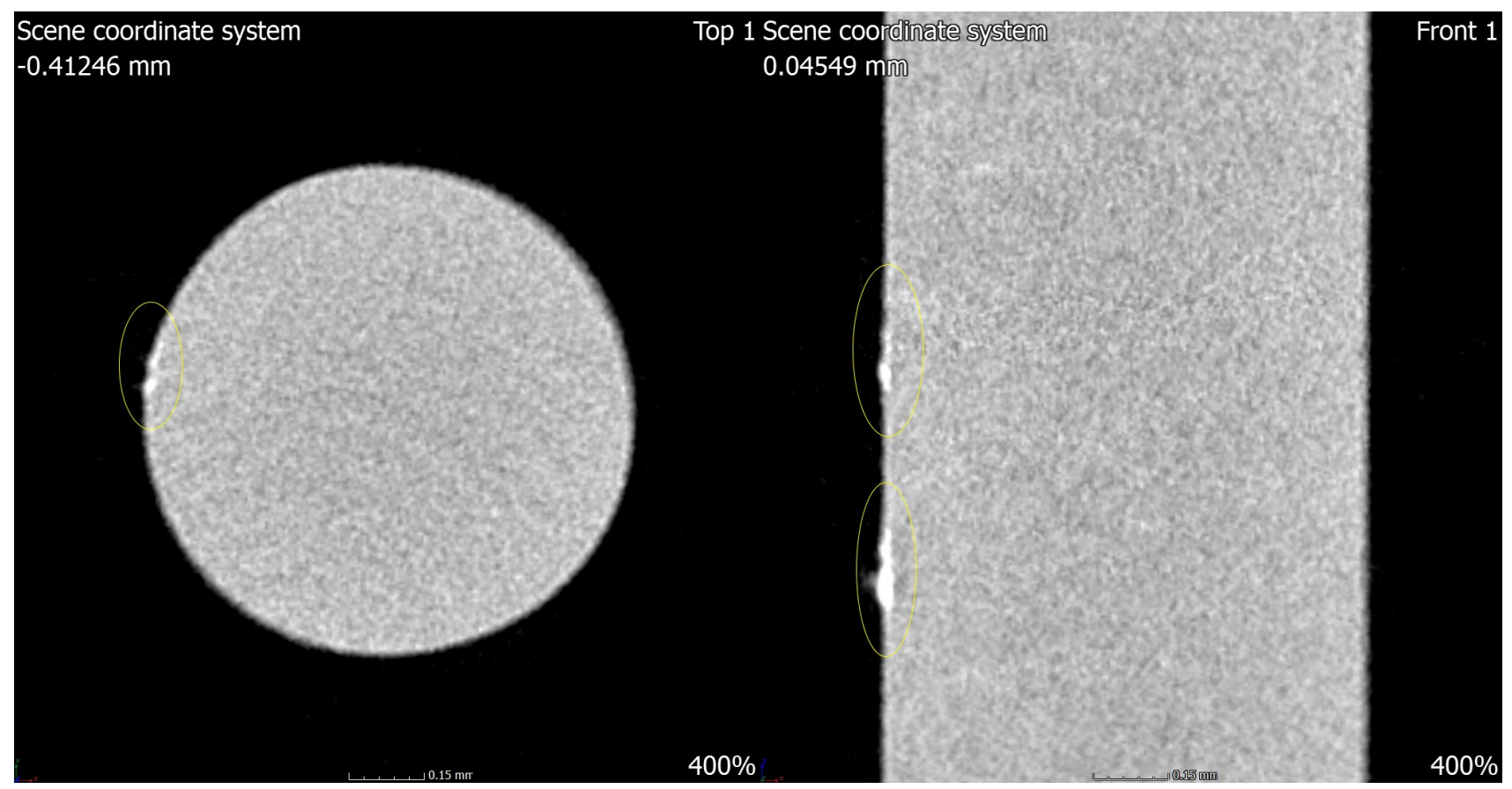

Fig. 12. Computed tomography scan BR2 M1-LOW-A. Areas of high density are highlighted. 


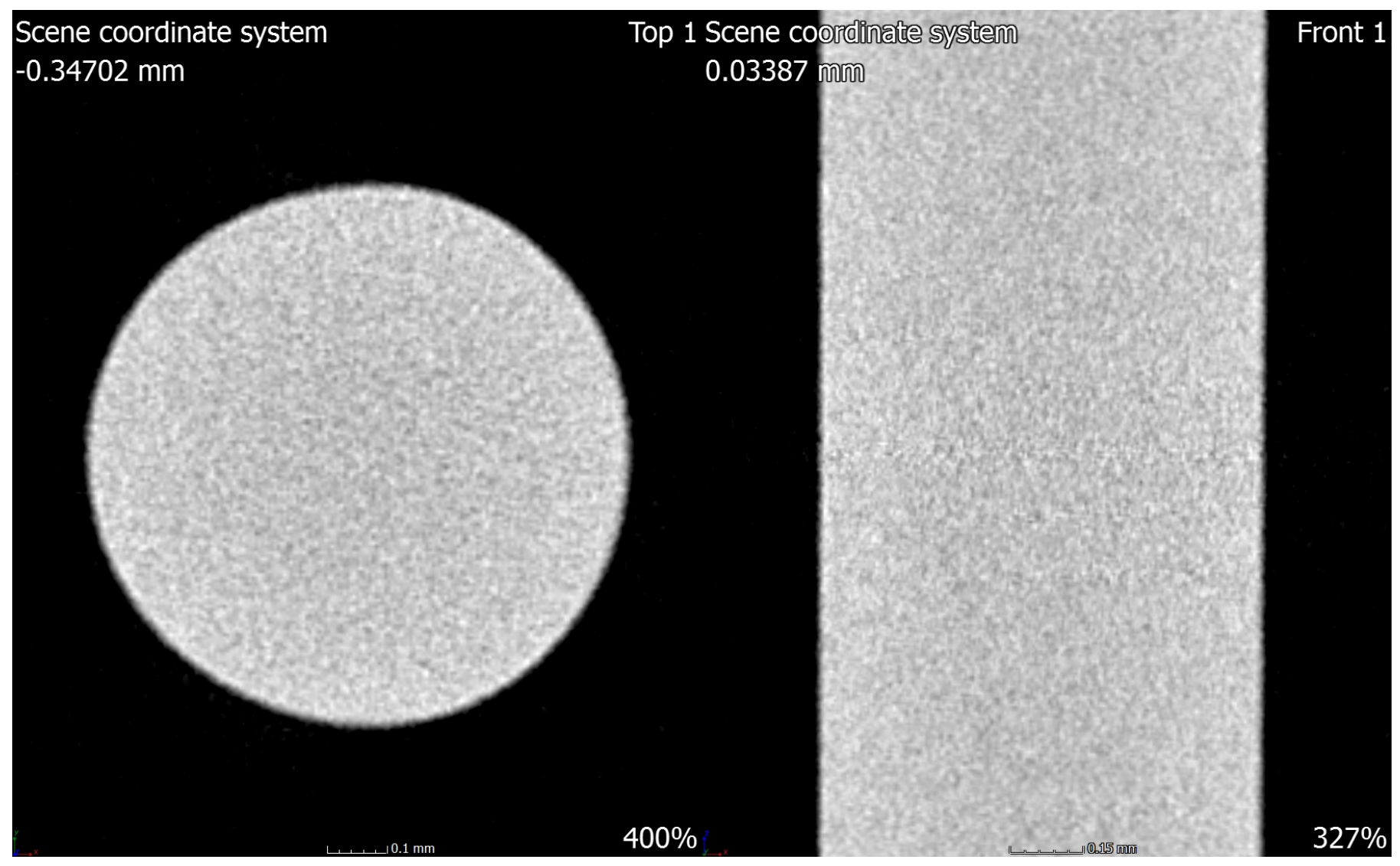

Fig. 13. Computed tomography scan BR2 M2-LOW-A. 